\title{
AMPA Receptors Are Involved in Store-Operated Calcium Entry and Interact with STIM Proteins in Rat Primary Cortical Neurons
}

\section{OPEN ACCESS}

Edited by:

Francesco Moccia, University of Pavia, Italy

Reviewed by: Menahem Segal, Weizmann Institute of Science, Israel Gaiti Hasan, National Centre for Biological Sciences, India

${ }^{*}$ Correspondence: Joanna Gruszczynska-Biegala joannag@iimcb.gov.pl

Received: 08 July 2016 Accepted: 13 October 2016 Published: 25 October 2016

Citation:

Gruszczynska-Biegala J, Sladowska M and Kuznicki J (2016) AMPA Receptors Are Involved in Store-Operated Calcium Entry and Interact with STIM Proteins in Rat

Primary Cortical Neurons.

Front. Cell. Neurosci. 10:251. doi: 10.3389/fncel.2016.00251

\author{
Joanna Gruszczynska-Biegala *, Maria Sladowska and Jacek Kuznicki \\ Laboratory of Neurodegeneration, International Institute of Molecular and Cell Biology in Warsaw, Warsaw, Poland
}

The process of store-operated calcium entry (SOCE) leads to refilling the endoplasmic reticulum (ER) with calcium ions $\left(\mathrm{Ca}^{2+}\right)$ after their release into the cytoplasm. Interactions between (ER)-located $\mathrm{Ca}^{2+}$ sensors (stromal interaction molecule 1 [STIM1] and STIM2) and plasma membrane-located $\mathrm{Ca}^{2+}$ channel-forming protein (Orai1) underlie SOCE and are well described in non-excitable cells. In neurons, however, SOCE appears to be more complex because of the importance of $\mathrm{Ca}^{2+}$ influx via voltage-gated or ionotropic receptor-operated $\mathrm{Ca}^{2+}$ channels. We found that the SOCE inhibitors ML-9 and SKF96365 reduced $\alpha$-amino-3-hydroxy-5-methyl-4-isoxazolepropionic acid (AMPA)-induced $\left[\mathrm{Ca}^{2+}\right]_{i}$ amplitude by $80 \%$ and $53 \%$, respectively. To assess the possible involvement of AMPA receptors (AMPARs) in SOCE, we used their specific inhibitors. As estimated by Fura-2 acetoxymethyl (AM) single-cell $\mathrm{Ca}^{2+}$ measurements in the presence of CNQX or NBQX, thapsigargin (TG)-induced $\mathrm{Ca}^{2+}$ influx decreased 2.2 or 3.7 times, respectively. These results suggest that under experimental conditions of SOCE when $\mathrm{Ca}^{2+}$ stores are depleted, $\mathrm{Ca}^{2+}$ can enter neurons also through AMPARs. Using specific antibodies against STIM proteins or GluA1/GluA2 AMPAR subunits, co-immunoprecipitation assays indicated that when $\mathrm{Ca}^{2+}$ levels are low in the neuronal ER, a physical association occurs between endogenous STIM proteins and endogenous AMPAR receptors. Altogether, our data suggest that STIM proteins in neurons can control AMPA-induced $\mathrm{Ca}^{2+}$ entry as a part of the mechanism of SOCE.

Keywords: store-operated calcium entry (SOCE), STIM, AMPA receptors, neurons, calcium signaling

\section{INTRODUCTION}

Neuronal $\mathrm{Ca}^{2+}$ homeostasis is precisely regulated by complex mechanisms (Berridge, 1998). Calcium ions activate various processes and are derived from the extracellular space or intracellular stores, such as the endoplasmic reticulum (ER). ER-dependent $\mathrm{Ca}^{2+}$ release occurs through the activation of $\mathrm{IP}_{3}$ receptors $\left(\mathrm{IP}_{3} \mathrm{Rs}\right)$ or ryanodine receptors (RyRs), leading to the depletion of $\mathrm{Ca}^{2+}$ stores (Berridge, 1998). Refilling these stores occurs through store-operated calcium entry (SOCE; Putney, 1986). This is the major mechanism that triggers $\mathrm{Ca}^{2+}$ influx in non-excitable cells (Parekh and Putney, 2005; Abdullaev et al., 2008; Sánchez-Hernández et al., 2010; Di Buduo et al., 2014). The key proteins that are involved in this process are $\mathrm{Ca}^{2+}$ sensors that are located in the ER (stromal interaction molecule 1 [STIM1] and 
STIM2) and $\mathrm{Ca}^{2+}$ channel-forming proteins (Orai1-3) that are present in the plasma membrane. Interactions between STIMs and Orais lead to the formation of complexes that are visible as puncta (Potier and Trebak, 2008; Shim et al., 2015) and result in $\mathrm{Ca}^{2+}$ entry into the cytoplasm from the extracellular space (Cahalan, 2009). STIMs can also induce $\mathrm{Ca}^{2+}$ influx via transient receptor potential (TRP) channels (Salido et al., 2011; Hartmann et al., 2014; Shin et al., 2016). $\mathrm{Ca}^{2+}$ that enters the cell is then transported to the ER through activity of the sarcoplasmic reticulum $\mathrm{Ca}^{2+}$-adenosine triphosphatase (SERCA) pump to refill ER stores and can be used for signaling (for review see Majewski and Kuznicki, 2015). In contrast to non-excitable cells, $\mathrm{Ca}^{2+}$ entry into neurons can occur via additional pathways. Two major pathways are voltage-gated $\mathrm{Ca}^{2+}$-channels (VGCCs) and ligand-gated $\mathrm{Ca}^{2+}$-channels (LGCCs), such as ionotropic glutamate receptors (Berridge, 1998; Clapham, 2007). Recent studies found that STIM-Orai-based SOCE mediates $\mathrm{Ca}^{2+}$ influx into cortical, hippocampal, dorsal root ganglion, and dorsal horn neurons (Klejman et al., 2009; Venkiteswaran and Hasan, 2009; Gemes et al., 2011; Koss et al., 2013; Xia et al., 2014). We found that both STIMs can form complexes with endogenous Orai1 (Gruszczynska-Biegala and Kuznicki, 2013) and are involved in $\mathrm{Ca}^{2+}$ homeostasis in cortical neurons. However, each STIM protein plays a distinct role in SOCE (Gruszczynska-Biegala et al., 2011; Hartmann et al., 2014). STIM1 activates SOCE when ER stores are depleted because of the activation of $\mathrm{IP}_{3} \mathrm{Rs}$, whereas STIM2 has lower affinity for $\mathrm{Ca}^{2+}$ than STIM1, and thus is responsible for constitutive $\mathrm{Ca}^{2+}$ influx in resting cells (Brandman et al., 2007). We demonstrated that STIM2 in cortical neurons, in contrast to STIM1, senses and reacts to small decreases in $\mathrm{Ca}^{2+}$ levels in the ER that are caused by lower intracellular $\mathrm{Ca}^{2+}$ levels (Gruszczynska-Biegala and Kuznicki, 2013).

Recent studies found that STIM1, in addition to Orai activation, inhibits $\mathrm{Ca}^{2+}$ entry that is mediated by $\mathrm{T}$ - and L-type channels in excitable cells (Park et al., 2010; Nguyen et al., 2013). Other studies reported that STIM2 is involved in the cyclic adenosine monophosphate (cAMP)/protein kinase A (PKA)-dependent phosphorylation of the $\alpha$-amino-3hydroxy-5-methyl-4-isoxazolepropionic acid (AMPA) receptor subunit GluAl by coupling PKA to the AMPA receptors (AMPARs) in a SOCE-independent manner (Garcia-Alvarez et al., 2015). However, no links have been established between STIM-dependent SOCE and AMPA-induced $\mathrm{Ca}^{2+}$ responses.

AMPARs are tetramers that are composed of homologous glutamate GluA1-GluA4 subunits in various combinations (Bigge, 1999) and are predominantly permeable for sodium and potassium ions. They also have $\mathrm{Ca}^{2+}$ permeability. However, when GluA2 is the dominant subunit, $\mathrm{Ca}^{2+}$ permeability is significantly diminished or even abolished (Hollmann and Heinemann, 1994). AMPARs are present in both neurons and glia and are involved in neuronal-glial communication in the cortex (Verkhratsky and Steinhäuser, 2000). Their subunit composition varies according to development, brain region and cell type (Song and Huganir, 2002).

In the present study, we analyzed the possible link between $\mathrm{Ca}^{2+}$ entry via AMPARs and SOCE in neurons. We found that SOCE was blocked by AMPAR antagonists and that SOCE inhibition decreased $\left[\mathrm{Ca}^{2+}\right]_{\mathrm{i}}$ rise that was induced by AMPAR agonist. These results, together with co-immunoprecipitation assays that indicated interactions between endogenous STIMs and AMPAR subunits, indicate the possible role of STIMs in AMPA-induced $\left[\mathrm{Ca}^{2+}\right]_{i}$ changes. These observations elucidate the role of STIM proteins in the influx of $\mathrm{Ca}^{2+}$ via channels other than Orai and TRPs.

\section{MATERIALS AND METHODS}

\section{Primary Cell Cultures}

Cortical neuronal cultures were prepared from embryonic day 19 (E19) Wistar rat brains. Pregnant female Wistar rats were provided by the Animal House of the Mossakowski Medical Research Centre, Polish Academy of Sciences (Warsaw, Poland). Animal care was in accordance with the European Communities Council Directive (86/609/EEC). The experimental procedures were approved by the Local Commission for the Ethics of Animal Experimentation no. 1 in Warsaw. Brains were removed from rat embryos and collected in cold Hanks solution supplemented with $15 \mathrm{mM}$ HEPES buffer and penicillin/streptomycin. The cortices were isolated, rinsed three times in cold Hanks solution, and treated with trypsin for $35 \mathrm{~min}$. The tissue was then rinsed in warm Hanks solution, washed three times, and dissociated by pipetting. For $\mathrm{Ca}^{2+}$ measurements, primary cortical neurons were plated at a density of $7 \times 10^{4}$ cells/well on eight-well PDL-laminin-precoated chamber slides (BioCoat). For the co-immunoprecipitation assays and Western blot, neurons were seeded on poly-D-lysine-precoated BioCoat plastic Petri dishes (BD Biosciences Discovery Labware) at a density of $7 \times 10^{6}$ cells/plate. Neurons were grown in Neurobasal medium (Invitrogen) supplemented with 2\% B27 (Invitrogen), $0.5 \mathrm{mM}$ glutamine (Sigma), $12.5 \mu \mathrm{M}$ glutamate (Sigma), and a penicillin $(100 \mathrm{U} / \mathrm{ml}) /$ streptomycin $(100 \mathrm{mg} / \mathrm{ml})$ mixture (Gibco). Cultures were maintained at $37^{\circ} \mathrm{C}$ in a humidified $5 \% \mathrm{CO}_{2} / 95 \%$ air atmosphere. Every 3-4 days, half of the conditioned medium was removed and replaced by fresh growth medium. The experiments were performed on 15-day-old cultures (co-immunoprecipitation assay, Western blot) or 16- to 17-day-old cultures ( $\mathrm{Ca}^{2+}$ measurements).

To make the glial cultures, a cortical cell suspension was plated on poly-D-lysine-precoated BioCoat plastic Petri dishes (BD Biosciences Discovery Labware) and grown in Dulbecco's Modified Eagle Medium (DMEM) that contained $10 \%$ fetal bovine serum and a penicillin $(100 \mathrm{U} / \mathrm{ml}) /$ streptomycin (100 $\mathrm{mg} / \mathrm{ml}$ ) mixture (Gibco). The cells were grown to confluence (after $\sim 1$ week) and were replated to avoid non-glial contamination. The medium was replaced once every 3-4 days. For Western blot, the cells were cultured for 15 days prior to the experiments.

\section{Cell Line Culture}

HeLa cells were grown in DMEM that contained $10 \%$ fetal bovine serum and a penicillin $(100 \mathrm{U} / \mathrm{ml}) /$ streptomycin $(100 \mathrm{mg} / \mathrm{ml})$ mixture (Gibco) at $37^{\circ} \mathrm{C}$ in a $5 \% \mathrm{CO}_{2}$ atmosphere. 


\section{Single-Cell $\mathrm{Ca}^{2+}$ Measurements}

Single-cell $\mathrm{Ca}^{2+}$ levels in cortical neurons were recorded using the ratiometric $\mathrm{Ca}^{2+}$ indicator dye Fura-2 acetoxymethyl ester (Fura-2 AM). Cells were grown on eight-well chamber slides and loaded with $2 \mu \mathrm{M}$ Fura-2 $\mathrm{AM}$ for $30 \mathrm{~min}$ at $37^{\circ} \mathrm{C}$ in Hanks Balanced Salt Solution (HBSS) that contained $145 \mathrm{mM} \mathrm{NaCl}$, $5 \mathrm{mM} \mathrm{KCl}, 0.75 \mathrm{mM} \mathrm{Na}_{2} \mathrm{HPO}_{4}, 10 \mathrm{mM}$ glucose, $10 \mathrm{mM}$ HEPES (pH 7.4) and $1 \mathrm{mM} \mathrm{MgCl}_{2}$ supplemented with $2 \mathrm{mM} \mathrm{CaCl}_{2}$ at $37^{\circ} \mathrm{C}$ (high $\mathrm{Ca}^{2+}$ medium) and then rinsed and left undisturbed for $30 \mathrm{~min}$ at $37^{\circ} \mathrm{C}$ to allow for de-esterification. Measurements of intracellular $\mathrm{Ca}^{2+}$ levels were performed every $1 \mathrm{~s}$ at $37^{\circ} \mathrm{C}$ using an Olympus $\mathrm{Scan}^{\wedge} \mathrm{R} \& \mathrm{Cell}^{\wedge} \mathrm{R}$ imaging system that consisted of an IX81 microscope (Olympus, Tokyo, Japan), 10 $\times$ 0.40 NA UPlanS Apo objective (Olympus, Tokyo, Japan), and Hamamatsu EM-CCD C9100-02 camera (Hamamatsu Photonics K.K., Hamamatsu City, Japan). Changes in intracellular $\mathrm{Ca}^{2+}$ concentration $\left(\left[\mathrm{Ca}^{2+}\right]_{\mathrm{i}}\right)$ in individual neuronal cell bodies are expressed as the F340/F380 ratio after subtracting background fluorescence. This ratio represents the emission intensities at $510 \mathrm{~nm}$ obtained after excitation at 340 and $380 \mathrm{~nm}$. The low $\mathrm{Ca}^{2+}$ medium $\left(\mathrm{Ca}^{2+}\right.$-free solution) contained $0.5 \mathrm{mM}$ ethylene glycol tetraacetic acid (EGTA) in the standard buffer. At the end of the experiments, $50 \mathrm{mM} \mathrm{KCl}$ in the presence of $2 \mathrm{mM} \mathrm{CaCl}_{2}$ was added to assess which cells were neurons (Figures 1, 2). Cells that responded with rapid, high $\left[\mathrm{Ca}^{2+}\right]_{\mathrm{i}}$ rise were identified as neurons and only these cells were analyzed in the experiments (Figures 1, 2). Approximately $60 \%$ of cells responded to $\mathrm{KCl}$, which is in line with previous studies (Orlandi et al., 2011). Cells that responded with a delay or did not respond at all were assumed to be non-neuronal glial cells, most likely astrocytes. Data processing was performed using Olympus Cell $^{\wedge} \mathrm{R}$ software.

\section{Co-Immunoprecipitation and Western Blot}

For the co-immunoprecipitation of endogenous STIM1, STIM2, GluA1, and GluA2 proteins, 15-day-old primary cortical neurons that were grown on Petri dishes were washed with cold phosphate-buffered saline (PBS), scraped and centrifuged at $1000 \times \mathrm{g}$ for $5 \mathrm{~min}$ at $4^{\circ} \mathrm{C}$. The pellet was suspended in lysate buffer, $\mathrm{pH} 7.5$, that contained $50 \mathrm{mM}$ Tris- $\mathrm{HCl}, 150 \mathrm{mM} \mathrm{NaCl}$, $0.1 \%$ sodium dodecyl sulfate (SDS), $0.5 \%$ sodium deoxycholate, $1 \%$ NP-40, and $1 \mathrm{mM}$ phenylmethylsulfonyl fluoride supplemented with complete Ethylenediaminetetraacetic acid (EDTA)-free protease inhibitor cocktail (Roche) and lysed with an insulin syringe $(18 \times)$. After incubation for $2 \mathrm{~h}$ on ice and centrifugation at $15,000 \times \mathrm{g}$ (neuronal lysates) for $20 \mathrm{~min}$ at $4^{\circ} \mathrm{C}$, cleared lysates were pre-incubated with $30 \mu \mathrm{l}$ of washed protein A-Sepharose (Roche) for $3 \mathrm{~h}$ at $4^{\circ} \mathrm{C}$. Sepharose resin and bound components were recovered by centrifugation at $15,000 \times \mathrm{g}$ for $20 \mathrm{~min}$ at $4^{\circ} \mathrm{C}$. Precleared lysates were subsequently incubated overnight at $4^{\circ} \mathrm{C}$ on a rocking platform with $30 \mu \mathrm{l}$ of A-Sepharose that was pre-incubated earlier for $3 \mathrm{~h}$ with $3 \mu \mathrm{g}$ of antibody (anti-STIM1, BD Transduction Laboratories or ProSci Inc., Poway, CA, USA; anti-STIM2, Santa Cruz Biotechnology, Santa Cruz, CA, USA; anti-GluA1, Abcam, UK; anti-GluA2, ProteinTech Group or Alomone Labs).
As a negative control when indicated, lysates were omitted or were incubated with anti-Flag (Sigma) or anti-IgG antibody (Sigma). Precipitated samples were then washed three times with repeated centrifugation, eluted in $50 \mu \mathrm{l}$ of $2 \times$ Laemmli Buffer. Protein extracts were resolved by $6 \%$ SDS-polyacrylamide gel electrophoresis (PAGE), transferred to a Protran nitrocellulose membrane (Whatman), and blocked for $2 \mathrm{~h}$ at room temperature in TBST (50 mM Tris- $\mathrm{HCl}$ [pH 7.5], $150 \mathrm{mM} \mathrm{NaCl}$, and $0.1 \%$ Tween 20) plus 5\% dry non-fat milk. Nitrocellulose sheets were then incubated in blocking solution with primary antibodies against STIM1 (1:200, ProteinTech Group), STIM2 (1:100, Alomone Labs), GluA1 (1:400, Merck Millipore) and GluA2 (1:300, ProteinTech Group) at $4^{\circ} \mathrm{C}$ overnight. The appropriate horseradish peroxidase-conjugated secondary antibody IgG (Sigma) was added at a dilution of $1: 10,000$ for $1 \mathrm{~h}$. The peroxidase was detected with a Chemiluminescent Substrate Reagent Kit (Novex ECL, Invitrogen).

On Western blot containing glial cells extracts, the optical density of the bands was estimated using a GS-800 Calibrated Densitometer and Quantity One software (Bio-Rad). GAPDH was run to normalize the protein loading.

\section{Statistical Analysis}

The statistical analysis was performed using Prism 5.02 software (GraphPad, San Diego, CA, USA). All of the data are expressed as mean \pm standard error of the mean (SEM), and differences were considered significant at $p<0.05$. Statistical significance was assessed using the nonparametric Mann-Whitney $U$ test for comparisons between the mean values of unpaired groups. All of the experiments were performed at least in triplicate.

\section{RESULTS}

\section{AMPA-Induced Changes in $\left[\mathrm{Ca}^{2+}\right]_{i}$ are Sensitive to the SOCE Inhibitors ML-9 and SKF96365}

The SOCE inhibitor ML9 was used to determine whether AMPA-induced $\left[\mathrm{Ca}^{2+}\right]_{\mathrm{i}}$ responses are affected. Rat cortical neurons were loaded with the Fura- $2 \mathrm{AM} \mathrm{Ca}^{2+}$ indicator in $2 \mathrm{mM} \mathrm{CaCl}_{2}$-containing medium, and the $\mathrm{Ca}^{2+}$ signal was recorded. The cells were then treated with $2 \mathrm{mM} \mathrm{Ca}^{2+}$ medium supplemented with $100 \mu \mathrm{M}$ AMPA in the absence or presence of $100 \mu \mathrm{M}$ ML-9. After the addition of AMPA, an increase in $\left[\mathrm{Ca}^{2+}\right]_{i}$ changes was observed in both neuronal cultures (Figure 1A). In control neurons, a long-lasting peak in cytosolic $\mathrm{Ca}^{2+}$ was observed with the AMPA stimulus. However, in the presence of ML-9, the $\left[\mathrm{Ca}^{2+}\right]_{\mathrm{i}}$ rise was lower and decreased to basal $\mathrm{Ca}^{2+}$ levels after approximately $1 \mathrm{~min}$ (Figure 1A). The data (expressed as the area under the curve [AUC]) revealed that AMPA-induced $\left[\mathrm{Ca}^{2+}\right]_{\mathrm{i}}$ amplitudes decreased by $80 \%$ in the presence of $100 \mu \mathrm{M}$ ML-9 (Figure 1G).

We next sought to determine whether AMPA-induced elevation in $\left[\mathrm{Ca}^{2+}\right]_{\mathrm{i}}$ in cortical neurons involves other receptors or channels. Neither the VGCC blocker nimodipine (NM; Figures 1C,G) nor $N$-methyl-D-aspartate (NMDA) receptor antagonist DAP-5 in the presence of NM (Figures 1D,G) 

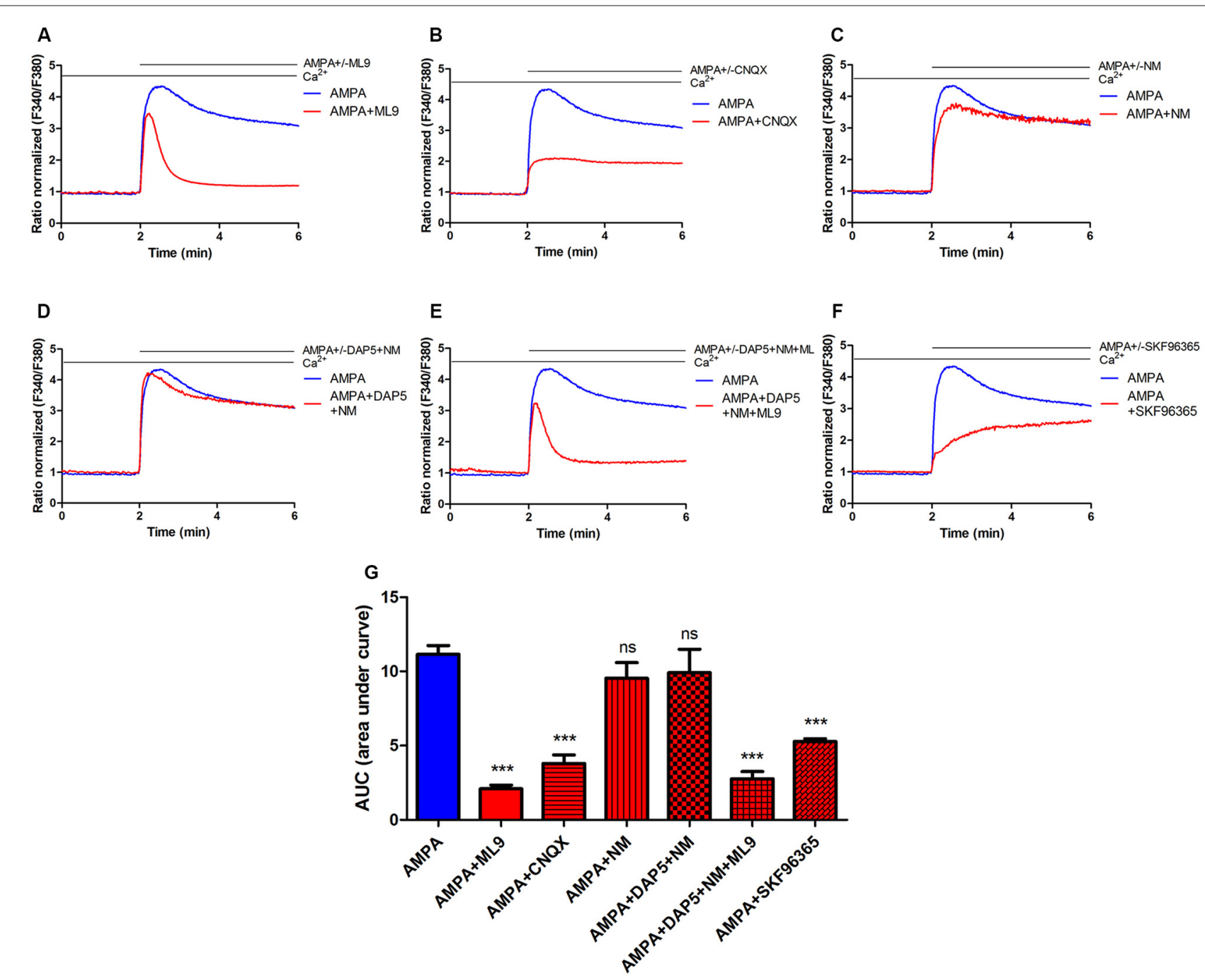

FIGURE 1 | Store-operated calcium entry (SOCE) inhibitor ML9 decreases $\alpha$-amino-3-hydroxy-5-methyl-4-isoxazolepropionic acid (AMPA)-induced changes in $\left[\mathrm{Ca}^{2+}\right]_{i}$ in rat cortical neurons. (A-F) Average traces of AMPA-induced intracellular $\mathrm{Ca}^{2+}$ (F340/F380) levels obtained by ratiometric Fura-2 acetoxymethyl (AM) analysis of untreated neurons (control) and neurons treated with indicated antagonists. Measurements were started in a buffer with $2 \mathrm{mM}$ CaCl 2 , then in a buffer that contained $100 \mu \mathrm{M}$ AMPA in the absence or presence indicated antagonists $100 \mu \mathrm{M}$ ML-9 (A) $30 \mu \mathrm{M}$ CNQX (B) $5 \mu \mathrm{M}$ nimodipine (NM; C) $10 \mu \mathrm{M}$ DAP-5 + $5 \mu \mathrm{M}$ NM (D) $10 \mu \mathrm{M}$ DAP-5 + $5 \mu \mathrm{M} \mathrm{NM}+100 \mu \mathrm{M}$ ML9 (E) $30 \mu \mathrm{M}$ SKF96365 (F). F340/F380 values just before the addition of the AMPAR agonist were normalized to the same values (1). The data represent $n$ independent experiments that were conducted on four different primary cultures, corresponding to 960 (AMPA, $n=17$ ), 677 (AMPA + ML9, $n=13$ ), 311 (AMPA + CNQX, $n=9$ ), 309 (AMPA + NM, $n=10), 258$ (AMPA + DAP5 + NM, $n=8$ ), 289 (AMPA + DAP5 + NM + ML9, $n=8$ ) and 95 (AMPA + SKF96365, $n=6$ ) analyzed cells that responded to KCl. (G) Summary data showing AMPA-induced changes in [Ca $\left.{ }^{2+}\right]_{i}$ in treated neurons compared with untreated neurons. The data are expressed as the AUC, which was calculated from the moment immediately before the addition of $\mathrm{Ca}^{2+}$. ${ }^{* * *} p<0.001 ;$ ns, not significant compared with the control (Student's $t$-test, Mann-Whitney $U$ test).

prevented AMPA responses. However, changes in $\left[\mathrm{Ca}^{2+}\right]_{\mathrm{i}}$ were highly abolished (by 66\%) by the AMPA/kainate receptor antagonist CNQX (Figures 1B,G). To reduce the effects of other channels on $\left[\mathrm{Ca}^{2+}\right]_{\mathrm{i}}$ responses, selective VGCC or NMDA receptor (NMDAR) blockers were applied in the presence of ML-9. Figure 1E shows that AMPA-induced $\left[\mathrm{Ca}^{2+}\right]_{\mathrm{i}}$ responses were reduced by ML- 9 in the presence of $\mathrm{NM}$ and DAP- 5 by $75 \%$, thus confirming its inhibitory effects. To further examine the impact of SOCE on AMPA-induced $\left[\mathrm{Ca}^{2+}\right]_{\mathrm{i}}$ response we used another SOCE inhibitor-SKF96365. In the presence of SKF96365 the AMPA-induced changes in $\left[\mathrm{Ca}^{2+}\right]_{\mathrm{i}}$ were decreased by $53 \%$ (Figures 1F,G). All these results suggest that intracellular $\left[\mathrm{Ca}^{2+}\right]_{i}$ elevations after AMPA stimulation in neuronal cultures occur primarily through AMPARs and store-operated channels and not through NMDARs or voltage-gated ion channels.

\section{SOCE in Neurons is Decreased by AMPA Receptor Antagonists}

Since the SOCE inhibitors blocked AMPA-induced $\left[\mathrm{Ca}^{2+}\right]_{\mathrm{i}}$ rise, we next investigated whether AMPAR activity participates in 

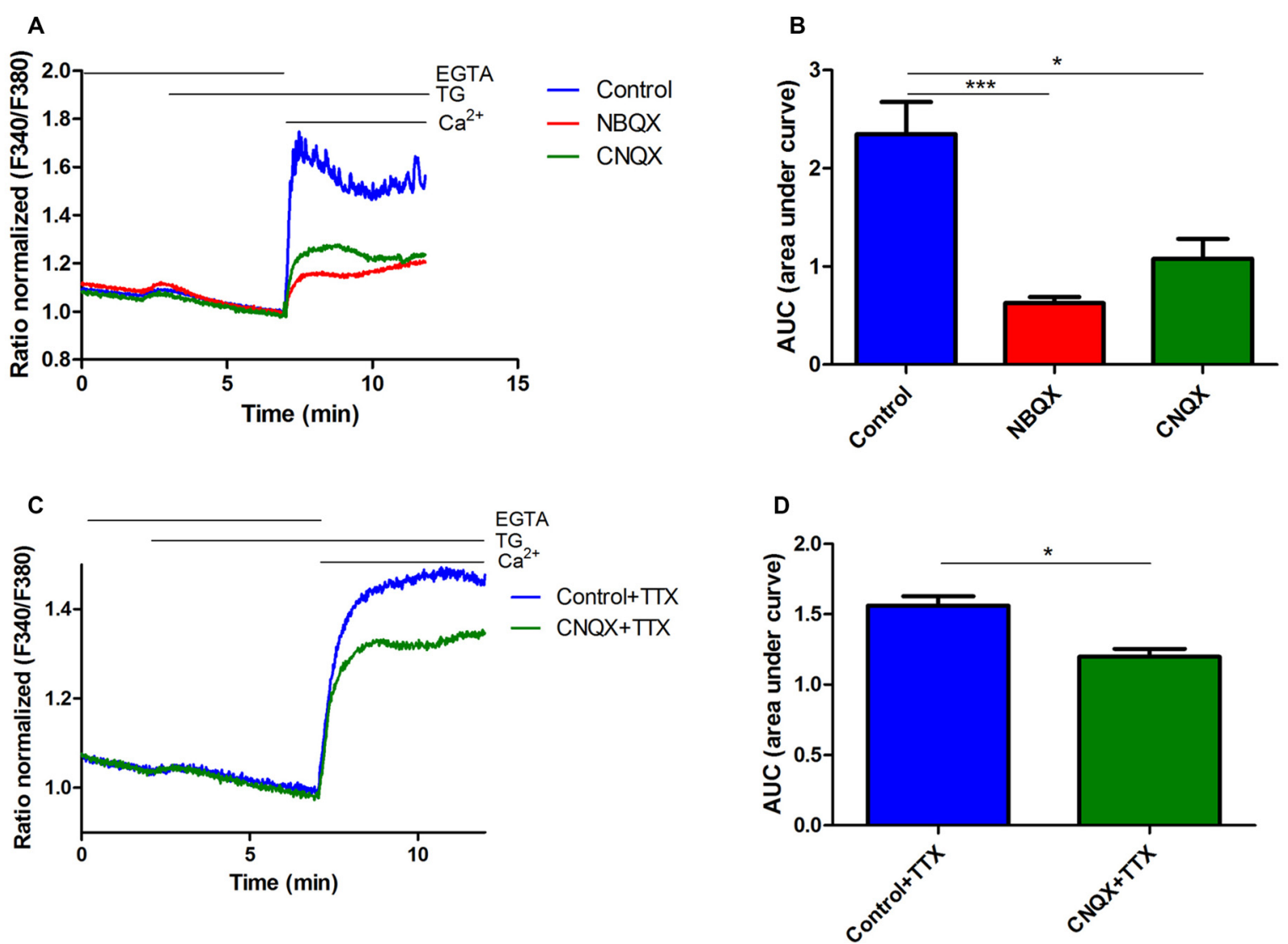

FIGURE 2 | Inhibition of thapsigargin (TG)-induced SOCE in rat cortical neurons by NBQX and CNQX. (A) Average traces of intracellular Ca ${ }^{2+}$ (F340/F380) levels obtained by ratiometric Fura-2 AM analysis of neurons treated with $30 \mu \mathrm{M}$ NBQX or $30 \mu \mathrm{M} C N Q X$ and untreated cultures (blue). Measurements were started in a medium with $0.5 \mathrm{mM}$ ethylene glycol tetraacetic acid (EGTA), which was then replaced by a medium with $0.5 \mathrm{mM}$ EGTA and either $2 \mu \mathrm{M}$ TG $+30 \mu \mathrm{M}$ NBQX or $2 \mu \mathrm{M} \mathrm{TG}+30 \mu \mathrm{M}$ CNQX. Finally, $2 \mathrm{mM} \mathrm{CaCl} 2$ was added to the medium to detect SOCE with either $30 \mu \mathrm{M}$ NBQX or $30 \mu \mathrm{M}$ CNQX. F340/F380 values just before the addition of $\mathrm{Ca}^{2+}$ were normalized to the same values (1). The data represent $n=28$ (control), $n=17$ (NBQX), and $n=13$ (CNQX) independent experiments that were conducted on three different primary cultures, corresponding to 1160,863 , and 516 analyzed cells that responded to $\mathrm{KCl}$, respectively. (C) Average traces of intracellular $\mathrm{Ca}^{2+}$ (F340/F380) levels obtained by ratiometric Fura-2 AM analysis of neurons treated with $30 \mu \mathrm{M} \mathrm{CNQX}+1 \mu \mathrm{M}$ TTX (green) and control cultures + $1 \mu \mathrm{M} \Pi \mathrm{TX}$ (blue). The data represent $n=3$ (control $+\pi \mathrm{X}$ ), and $n=3(\mathrm{CNQX}+\pi \mathrm{X})$ independent experiments that were conducted on one primary culture, corresponding to 64 and 72 analyzed cells that responded to $\mathrm{KCl}$, respectively. (B,D) Summary data showing SOCE as the AUC, which was calculated from the moment immediately before the addition of $\mathrm{Ca}^{2+} .{ }^{\star \star \star} p<0.001,{ }^{*} p<0.05$, compared with the control [Student's $t$-test, Mann-Whitney $U$ test (B); $t$-test, unpaired test (D)].

SOCE. We used the potent AMPAR antagonists CNQX and NBQX. $\mathrm{Ca}^{2+}$ recordings were performed in rat cortical neurons. Cells were loaded with the Fura- $2 \mathrm{Ca}^{2+}$ indicator in $2 \mathrm{mM} \mathrm{CaCl}_{2}$ containing medium and then incubated with $0.5 \mathrm{mM}$ EGTA medium to initiate the measurements. The neuronal cultures were then treated with thapsigargin (TG) and either NBQX or CNQX. After $5 \mathrm{~min}$, a medium with $2 \mathrm{mM} \mathrm{CaCl} 2$ was added to induce SOCE in the presence of $30 \mu \mathrm{M}$ NBQX or $30 \mu \mathrm{M}$ CNQX. To distinguish neurons from other cells that were present in the culture, $\mathrm{KCl}$ was added at the end of the experiments, and the $\mathrm{Ca}^{2+}$ signal was recorded (data not shown). Only cells that responded with fast and transient increases in $\mathrm{Ca}^{2+}$ were considered neurons (Figure 2). To eliminate the possible effect of synapses activation on SOCE, we used $1 \mu \mathrm{M}$ tetrodotoxin (TTX), which prevents firing. The addition of $\mathrm{Ca}^{2+}$ to the medium increased intracellular $\mathrm{Ca}^{2+}$ levels under all of the tested conditions (Figure 2A). These effects were substantially blunted by exposing the neurons to the AMPAR antagonists. Treatment with NBQX and CNQX suppressed TG-induced SOCE in neurons by $73 \%$ and $55 \%$, respectively, compared with control cells (Figure 2A), reflected by a decrease in the AUC (Figure 2B). SOCE responses were also reduced by CNQX in the presence of TTX by 23\% (Figures 2C,D). These results suggest that AMPARs are involved in SOCE in rat cortical neurons and may be activated after TG-induced $\mathrm{Ca}^{2+}$ store depletion.

\section{Differential Effects of NBQX on SOCE in Glia and Neurons}

In the above experiments, cells in culture that did not respond to $\mathrm{KCl}$ were considered glial cells. The data that were collected 

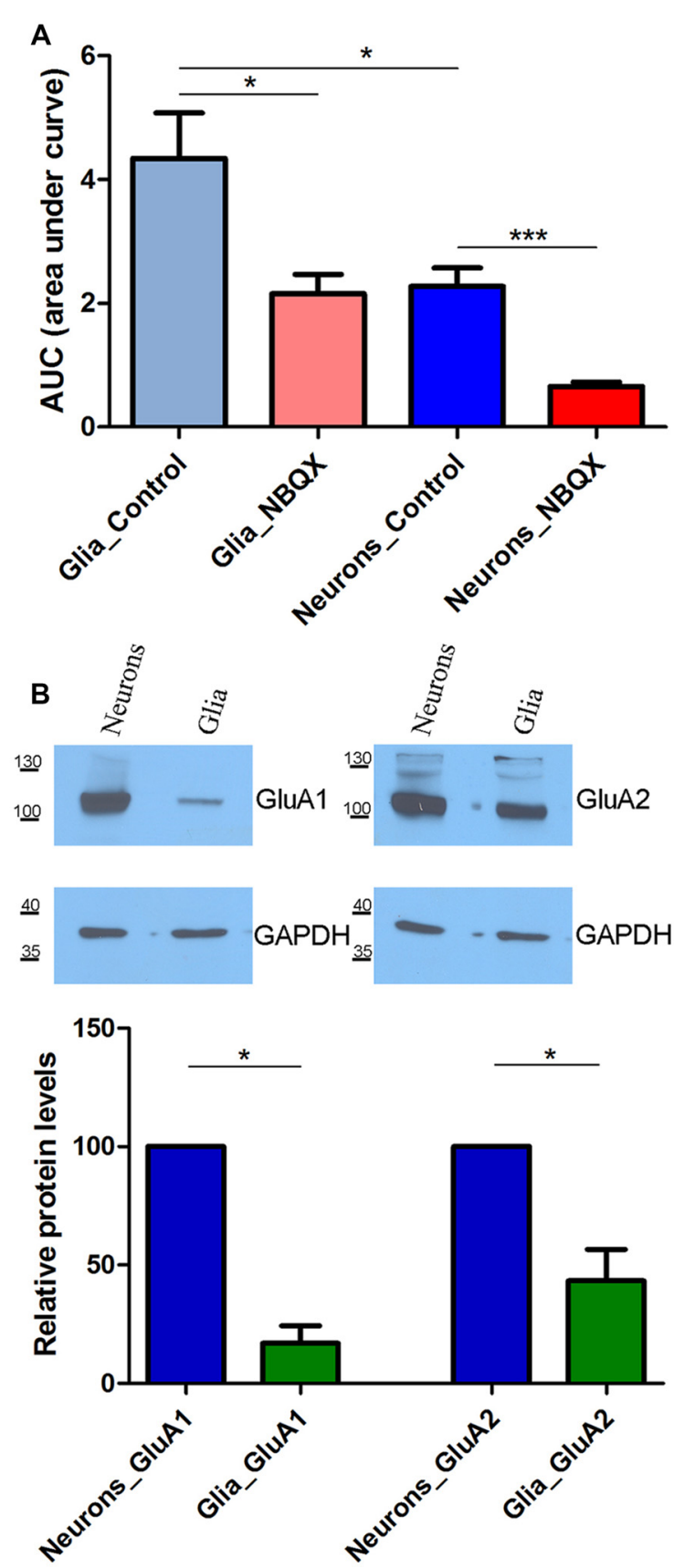

FIGURE 3 | SOCE analysis in glia and neurons in the presence of $\mathbf{3 0} \boldsymbol{\mu} \mathbf{M}$ NBQX. (A) Experiments were performed as described in Figure 2 SOCE is shown as the AUC, which was calculated from the moment immediately before the addition of $\mathrm{Ca}^{2+}$. The number of recorded cells was 470 glial cells, 503 glial cells in the presence of NBQX, 869 neurons, and 863 neurons in the presence of NBQX. ${ }^{* * *} p<0.001,{ }^{*} p<0.05$ (Student's $t$-test, Mann-Whitney $U$ test). (B) Expression of AMPA receptors (AMPARs) GluA1 and GluA2 subunits in whole-cell cortical lysates from neurons and glia. GAPDH was used as a loading control. The molecular masses of the markers that were run on the same gel are shown on the left. Bars indicate the quantification of Western blots showing the GluA1 and GluA2 levels normalized to the level of GAPDH. Values are expressed as a percentage of protein levels in neurons. The blots were performed four times from four independent cultures. ${ }^{*} p<0.05$ (Student's $t$-test, Mann-Whitney $U$ test). for these cells were also analyzed (Figure 3A). Consistent with our previously published results (Steinbeck et al., 2011), TG-induced SOCE was higher in glial cells than in neurons, with an approximately two-fold difference in SOCE (indicated by the AUC). Glial SOCE was decreased by $46 \%$ by $30 \mu \mathrm{M}$ NBQX, whereas neuronal SOCE was decreased by $73 \%$ in these cultures (Figure 3A).

We next investigated whether this difference can be explained by the expression of different AMPAR subunits in neurons and glia. To examine the protein expression of the AMPAR GluA1 and GluA2 subunits, Western blot was performed using lysates from cultures of neuronal and glial cells that were grown separately. Both GluA1 and GluA2 were detected in neurons. In glial cells, they markedly decreased or were barely detectable (Figure 3B). The densitometric analysis of the band intensities in four experiments indicated that there was 5.9 and 2.3 times more GluA1 and GluA2 in neurons than in glia, respectively $\left({ }^{*} p<0.05\right.$; bars on Figure 3B). These data indicate that neuronal SOCE is more sensitive to NBQX than glial SOCE, likely because of the higher expression of AMPAR subunits in neurons.

\section{No Effect of AMPAR Antagonists on SOCE in HeLa Cells}

To exclude the possibility that NBQX inhibits SOCE by interacting with the STIM/Orai complex, we tested its effect in HeLa cells, which lack AMPARs. The treatment of HeLa cells with $30 \mu \mathrm{M}$ NBQX did not affect the average peak of TG-induced $\mathrm{Ca}^{2+}$ release (Figure 4A, first peak) and only slightly decreased SOCE (Figure 4A, second peaks). The observed difference was not statistically significant (Figures $4 \mathrm{~B}, \mathrm{C}$ ). These results indicate that NBQX does not inhibit SOCE in neurons directly but rather inhibits SOCE by decreasing AMPAR activity.

\section{STIM1 and STIM2 Interact with AMPA Subunits in Rat Cortical Neurons}

The data above suggest a relationship between AMPARs and SOCE. To confirm the observed participation of AMPARs in $\left[\mathrm{Ca}^{2+}\right]_{\mathrm{i}}$ elevation under SOCE conditions, we evaluated whether endogenous STIM proteins interact with endogenous AMPAR subunits. We performed co-immunoprecipitation experiments using extracts of cultures of rat cortical neurons that were treated with TG to induce SOCE. Specific STIM1, STIM2, GluA1, and GluA2 antibodies were used, and the immunoprecipitates were analyzed by Western blot. Anti-Flag antibodies and IgG were used to identify possible nonspecific interactions. When the neuronal lysates were immunoprecipitated with the anti-STIM1 antibody, the bands of GluA1 (Figure 5A) and GluA2 (Figure 5B) were detected in the immunoprecipitates. The presence of both GluA1 and GluA2 was also detected in the immunoprecipitates of STIM2 (Figures 5A,B). Both subunits were missing in the negative control samples without the lysate. A very weak band of GluA1 and no band of GluA2 were observed in the immunoprecipitates with anti-Flag antibody. These data indicated that STIM1 and STIM2 may physically associate 

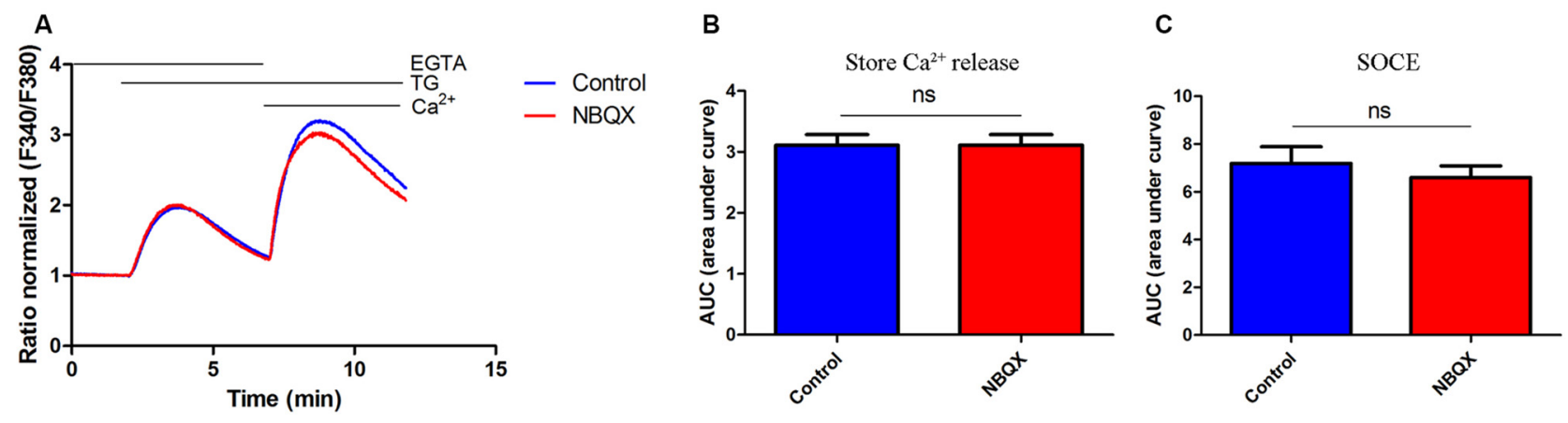

FIGURE 4 | NBQX did not block TG-induced SOCE in HeLa cells. (A) Average traces of intracellular Ca ${ }^{2+}$ (F340/F380) levels obtained by ratiometric Fura-2 AM analysis of cells treated with $30 \mu \mathrm{M} \mathrm{NBQX}$ (red line) and untreated cells (blue line). Measurements were conducted as described in Figure 2. F340/F380 values just before the addition of TG were normalized to the same values (1). The data represents 16 independent measurements conducted in three different experiments, corresponding to 1300 for control cells and 1000 for NBQX cells. (B,C) Summary data presented as the AUC, showing TG-induced Ca ${ }^{2+}$ release from the endoplasmic reticulum (ER), which was calculated from the moment of the addition of TG until extracellular Ca ${ }^{2+}$ was added (B) or SOCE, which was calculated from the moment immediately before the addition of $\mathrm{Ca}^{2+} \mathbf{( C )}$. ns, not significant (Student's $t$-test, Mann-Whitney $U$ test).

with AMPAR subunits in cultures of rat cortical neurons (Figures 5A,B).

In reverse experiments, in which neuronal lysates were immunoprecipitated with anti-GluA1 antibody (Figures 5C,D) or anti-GluA2 antibody (Figures 5E,F), the presence of STIM1 (Figures 5C,E) or STIM2 (Figures 5D,F) was detected. Samples with omitted lysates that were probed for STIM1 or STIM2 did not show any GluA1. No interactions were found between control IgG and STIM proteins in anti-GluA immunoprecipitates (Figures 5E,F). No STIM bands were detected in the Flag immunoprecipitates (Figures 5C-F). Our co-immunoprecipitation experiments indicate that STIM1 and STIM2 qualitatively associate with GluA1 and GluA2. This supports the calcium imaging data.

\section{DISCUSSION}

The major $\mathrm{Ca}^{2+}$ influx pathway in neurons is through VGCCs and ionotropic glutamate receptors (Verkhratsky and Kettenmann, 1996). However, previous studies also demonstrated the presence of SOCE in cultured neurons (Emptage et al., 2001; Kachoei et al., 2006; Berna-Erro et al., 2009; Klejman et al., 2009; Gruszczynska-Biegala et al., 2011). Additionally, the SOCE component STIM1 does not only activate Orai1, but it also modulates the activity of $\mathrm{Ca}_{V} 1.2$ (Park et al., 2010; Harraz and Altier, 2014) and Cav3.1 (Nguyen et al., 2013) VGCCs, the plasma membrane $\mathrm{Ca}^{2+}$ adenosine triphosphatase pump (Krapivinsky et al., 2011), and metabotropic glutamate one receptor-dependent TRPC3 (Hartmann et al., 2014). The results demonstrate that STIM proteins may impact various $\mathrm{Ca}^{2+}$ related pathways in neurons (Harraz and Altier, 2014; Kraft, 2015; Majewski and Kuznicki, 2015; Moccia et al., 2015).

The major finding in the present study was the functional relationship between SOCE, STIM proteins and ionotropic AMPARs. We showed that interactions between endogenous STIM1/STIM2 and AMPAR GluA subunits occur in cortical neurons and that SOCE-dependent mechanisms affect
AMPA-mediated $\left[\mathrm{Ca}^{2+}\right]_{\mathrm{i}}$ rise. TG-induced SOCE was decreased 2.2-3.7 times in the presence of the potent competitive AMPAR antagonists CNQX and NBQX, suggesting that $\mathrm{Ca}^{2+}$ store depletion leads to $\mathrm{Ca}^{2+}$ influx by AMPARs. There exists a possibility that addition of calcium activates synapses, causing a large increase in network activity, and consequently an influx of calcium through NMDA and AMPARs. Indeed, Baba et al. (2003) suggested that in hippocampal pyramidal neurons SOCE can contribute to synaptic activity. We show that blocking the activity by TTX does not remove the inhibition of SOCE by CNQX, which confirms that SOCE is still mediated by AMPAR blockade (Figures 2C,D). Moreover, to minimalize an influx through the NMDAR, the $\mathrm{Ca}^{2+}$ imaging experiments were performed in the presence of $\mathrm{Mg}^{2+}$ ions, when the initial glutamate-induced $\left[\mathrm{Ca}^{2+}\right]_{\mathrm{i}}$ peak is severely blunted. As the membrane depolarizes, the $\mathrm{Mg}^{2+}$ blockage is removed (Nowak et al., 1984). However, Kachoei et al. (2006) demonstrated that the source of $\mathrm{Ca}^{2+}$ during SOCE appears to be solely from the SOCE pathway, given that the depolarization is too small to bring the membrane potential near the threshold for activation of the voltage-gated $\mathrm{Ca}^{2+}$ channels. The decrease in SOCE in neurons was attributable to the inhibition of $\mathrm{Ca}^{2+}$ influx through AMPARs, which was supported by observations in HeLa cells, which do not possess AMPARs, in which SOCE and Orai channels were unaffected by NBQX. We propose that the induction of SOCE by TG leads to the activation of Orai, but also to activation of AMPARs either directly through the recruitment of AMPARs by STIM proteins or indirectly through unknown mechanisms.

STIM2 was recently proposed to shape basal transmission in excitatory neurons and is involved in the formation of dendritic spines and essential for the cAMP/PKA-dependent phosphorylation of AMPARs (Garcia-Alvarez et al., 2015). These authors speculated that STIM2 might regulate various forms of synaptic plasticity by managing GluA1-PKA coupling at excitatory synapses. They also performed 

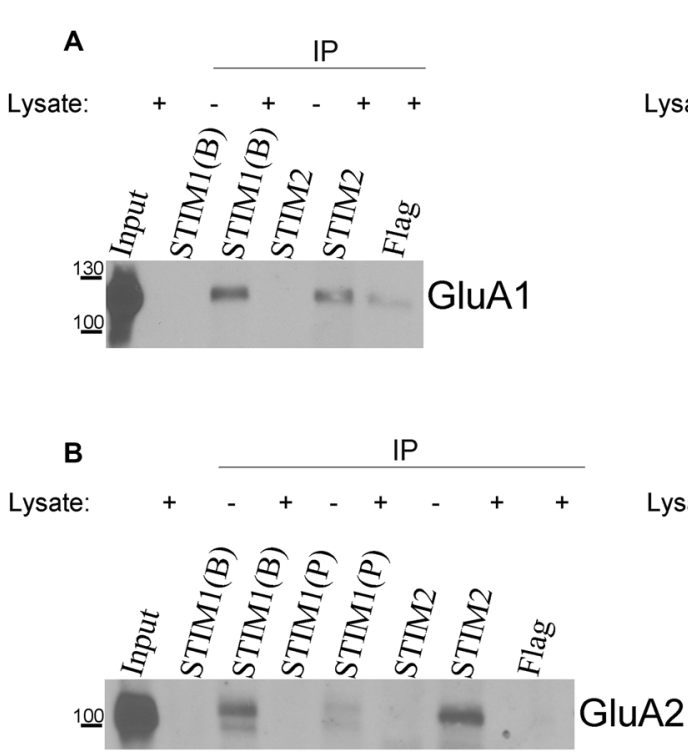

D
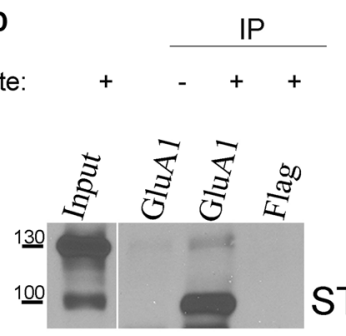

STIM2

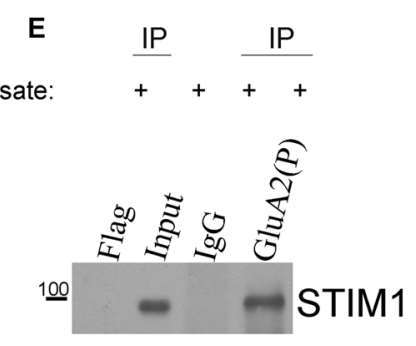

F
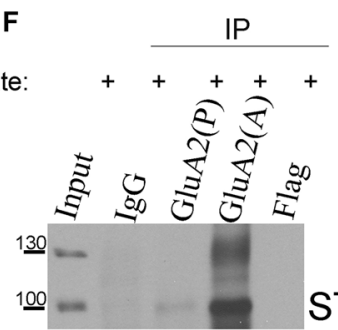

STIM2

FIGURE 5 | Co-immunoprecipitation of endogenous stromal interaction molecule 1 (STIM1) and STIM2 with GluA1 and GluA2 in lysates of neuronal cultures. Neurons were treated with TG for 10 min and lysed. Proteins were immunoprecipitated with (A,B) anti-STIM1 (BD Transduction Laboratories [B], ProSci [P]), (A,B) anti-STIM2, (C,D) anti-GluA1, or (E,F) anti-GluA2 (Proteintech [P], Alomone [A]) antibodies. Lysates (Inputs) and eluted fractions (immunoprecipitates, IP) were separated on 6\% sodium dodecyl sulfate (SDS)-PAGE gels, and proteins were identified by Western blot using anti-GluA1, GluA2, STIM1, or STIM2 antibodies as indicated. When indicated, the lysates were omitted in the probes. Irrelevant mouse or rabbit anti-Flag and/or rabbit anti-lgG antibodies were used as negative controls. The molecular masses of the markers that were run on the same gel are shown on the left. Immunoprecipitation was performed three times from three different cultures with the same positive outcome.

co-immunoprecipitation assays and reported an interaction between the AMPAR GluA1 subunit and STIM2 in rat brains and in neurons that overexpressed yellow fluorescent protein (YFP)-STIM2. Our co-immunoprecipitation results confirmed the physical interaction between GluA1 and STIM2 and further demonstrated that endogenous STIM1 interacts with GluA1, and both endogenous STIM proteins interact with GluA2. These physical interactions were observed under conditions of SOCE, suggesting that STIM-AMPAR interactions result from $\mathrm{Ca}^{2+}$ store depletion. $\mathrm{Ca}^{2+}$ imaging data show that AMPARs are functional which indicates that they are located on the plasma membrane. Previously, we demonstrated that cultures of primary cortical neurons STIM proteins were present only in the membrane fraction (but not in cytosolic fraction) and the TG-treatment increased the level of both proteins in the membrane fractions (GruszczynskaBiegala et al., 2011). Since the co-immunoprecipitation experiments were performed after TG treatment, it seems that the STIM-AMPAR association takes place in the membrane fractions, most probably at the ER-plasma membrane junctions. STIM2 was previously shown to promote the PKA-dependent surface delivery of GluA1 (Garcia-Alvarez et al., 2015). STIM1 prevents the surface expression of Cav1.2 (Park et al., 2010) and $\mathrm{Ca}_{V} 3.1$ (Nguyen et al., 2013), but it is unknown whether STIM1 also augments the surface expression of AMPARs.

In the cerebral cortex of mammals majority of pyramidal cells (glutamatergic) contains GluA2 subunit of AMPAR, whereas non-pyramidal cells (mainly GABAergic inhibitory interneurons) preferentially express GluA1-specific mRNA (Martin et al., 1993; Jonas et al., 1994). For example, neocortical layer $\mathrm{V}$ pyramidal neurons contained approximately $9 / 75 / 13 / 3 \%$ of GluA-1/2/3/4 subunits, while neocortical layer IV non-pyramidal neurons contained 57/24/13/6 GluA$1 / 2 / 3 / 4$ subunits, respectively (Jonas et al., 1994). Our previous studies reported the presence of strong immunostaining for STIM1 in pyramidal neurons of layer $\mathrm{V}$ of the cerebral cortex. In the other cortical layers, immunostained cell profiles were present, although the intensity of the signals was weaker than that observed in layer V. Granular layer IV with majority of interneurons had lowest signal (Klejman et al., 2009; Skibinska-Kijek et al., 2009). Expression of STIM2 in the neuronal cell types of cortex has not been investigated so far. Given that in the neocortex approximately $20-30 \%$ of neurons are interneurons (Markram et al., 2004), we may speculate that the association between GluA1 or GluA2 with STIM1 or STIM2 occurs mainly in pyramidal cells. However, due to the high expression of GluA1 in non-pyramidal cells this interaction may also take place in these cells.

ML-9 is a myosin light chain kinase (MLCK) inhibitor that is commonly used to inhibit SOCE (Watanabe et al., 1996; Smyth et al., 2008; Potier et al., 2009; GruszczynskaBiegala et al., 2011; Steinbeck et al., 2011; Li et al., 2013; Lin et al., 2016; Wang et al., 2016). We found that $\left[\mathrm{Ca}^{2+}\right]_{\mathrm{i}}$ amplitudes activated by AMPA decreased in the presence of 
ML-9. Moreover, the peak in cytosolic $\mathrm{Ca}^{2+}$ was transient in the presence of ML-9, in contrast to the long-lasting peak that was observed with AMPA stimulation alone, suggesting that SOC may be responsible for the prolonged AMPA-induced $\left[\mathrm{Ca}^{2+}\right]_{i}$ responses in rat cortical neurons. The response to AMPA stimulation was unaffected by the VGCC antagonist NM alone or in combination with the NMDAR antagonist DAP-5 but was abolished when NM and DAP-5 were added together with ML-9. Thus, the SOCE antagonist ML-9 inhibited $\mathrm{Ca}^{2+}$ influx through AMPARs, but the mechanism of this activity is unclear. Our previous study found that ML-9 decreased SOCE by $\sim 65 \%$ in rat cortical neurons (Gruszczynska-Biegala et al., 2011). Although the site of action of ML-9 on STIM1 remains unknown, it seems to have an inhibitory effect on SOCE by either preventing or reversing STIM puncta formation (Smyth et al., 2008). Since ML-9 is an MLCK antagonist, one possibility is that AMPAR inhibition is achieved through this mechanism. Resolving this issue is especially important because MLCK inhibitors depress NMDAR-mediated currents and NMDA miniature excitatory postsynaptic currents in hippocampal neurons (Lei et al., 2001). These observations imply that an intact cytoskeleton is required for the basal regulation of NMDARs by MLCK. However, they also indicate that MLCK does not affect AMPAR-mediated currents, suggesting that this kinase specifically modulates NMDAR function (Lei et al., 2001).

The inhibitory effect of ML-9 on SOCE is not completely understood, but it seems to be unrelated to the inhibition of MLCK. Earlier work revealed that knocking down MLCK using siRNA or wortmannin (another MLCK inhibitor) does not affect SOCE or STIM1 redistribution (Smyth et al., 2008). In HEK293 cells that overexpressed YFP-STIM1, ML-9 significantly reduced the number of STIM1-Orail puncta structures (Smyth et al., 2008). In primary neuronal cultures, ML-9 also decreased the number of endogenous STIM1-Orail puncta (GruszczynskaBiegala and Kuznicki, 2013). Assuming that ML-9 is a modulator of STIM1 translocation, we postulated that STIM1 interacts with AMPARs. Our co-immunoprecipitation results in the present study supported this hypothesis. Since STIM2 also associates with both AMPAR subunits it is likely that this $\mathrm{Ca}^{2+}$ sensor is also affected by ML-9. Indeed, we previously demonstrated that ML-9 inhibits STIM2 enrichment in the membrane fraction after store depletion (Gruszczynska-Biegala et al., 2011). Some studies have shown that ML-9 also antagonizes cAMP-dependent PKA and protein kinase $\mathrm{C}$ at the concentration used in this study (Saitoh et al., 1987; Bain et al., 2003). To be sure that AMPA-induced $\left[\mathrm{Ca}^{2+}\right]_{\mathrm{i}}$ response was decreased by blockade of SOCE we applied another commonly used SOCE blocker-SKF96365 and found that it also significantly suppressed the AMPA-induced changes in $\left[\mathrm{Ca}^{2+}\right]_{i}$. These results confirm that some of SOCE-responsive proteins are involved in AMPA-induced $\left[\mathrm{Ca}^{2+}\right]_{i}$ rise. The discrepancy between inhibitory effect of ML-9 and SKF96365 on AMPA-induced $\left[\mathrm{Ca}^{2+}\right]_{\mathrm{i}}$ amplitude (Figures 1A,F) is probably due to the different selectivity of these inhibitors for SOCE. It was shown that SKF96365 is able to inhibit TRP channels as well (reviewed in Prakriya and Lewis, 2015), which could explain different kinetics of the $\left[\mathrm{Ca}^{2+}\right]_{\mathrm{i}}$ responses. Moreover, the mechanism by which these compounds exert their inhibitory effects could be different. Since ML-9 and SKF96365 seem to be rather STIM-mediated $\mathrm{Ca}^{2+}$ influx inhibitors (reviewed in Majewski and Kuznicki, 2015), it suggests their major role in the rise in $\left[\mathrm{Ca}^{2+}\right]_{i}$ induced by AMPA. Other potential mechanism, including the plasma membrane protein Orai may also be involved. Orai may enhance STIM recruitment to the proximity of AMPARs by effectively trapping STIM in puncta as was shown in the case of $\mathrm{Ca}_{V} 1.2$ channels (Wang et al., 2010). We cannot exclude the existence of AMPARSTIM-Orai complex. However, it was shown recently that Orai does not interact with GluA1 in YFP-STIM2-expressing hippocampal neurons and in rat brains. This implies that the two machineries (STIM2/GluA1 and STIM/SOCE) are not necessarily coupled (Garcia-Alvarez et al., 2015). Further work will be required to establish the exact mechanism of AMPARSTIM-Orai interaction. Another question arises, whether in glutamate-stimulated neurons, STIM/Orail and STIM/AMPARs work independently or interact during $\mathrm{Ca}^{2+}$ entry. SOCE might be a key mediator of glutamate-induced HT-22 cell injury. Recently, it was shown that in these cells the levels of STIM1 or Orail proteins did not change after glutamate treatment, whereas glutamate provoked a redistribution of STIM1 into puncta within the cell, and might cause STIM1-mediated calcium influx (Rao et al., 2016). Moreover, increased Homerla protein levels significantly inhibited SOCE and decreased the association of STIM1-Orail triggered by glutamate. However, the detailed mechanisms of interaction between glutamate receptors and STIM proteins will have to be further studied.

It is well known that a sustained $\mathrm{Ca}^{2+}$ entry is linked to Ins $\mathrm{P}_{3}$-dependent $\mathrm{Ca}^{2+}$ store depletion induced by activation of metabotropic glutamate receptors (Berridge, 1998). In this way glutamate activates SOCE by recruiting STIM1 and Orai1. Since we show that AMPA responses are not mediated by VGCC or by NMDARs, it would be interesting to investigate if responses to glutamate are not mediated by SOCE either. Noteworthy, in culture of rat cortical astrocytes at higher concentration of agonist additional $\mathrm{Ca}^{2+}$ influx pathway activated by glutamate was found. This influx pathway, attributable to AMPA/kainite receptors, is sensitive to NBQX but insensitive to SOCE blocker $\mathrm{La}^{3+}$ (Pizzo et al., 2001).

In the present study, we found that SOCE in neurons was approximately two-times lower than in glial cells. This seems to reflect the larger size of $\mathrm{Ca}^{2+}$ stores in glia, in which TG-induced SOCE should lead to greater $\mathrm{Ca}^{2+}$ influx than in neurons. Similar observations were described previously (Arakawa et al., 2000; Steinbeck et al., 2011). Another possibility is that the dissimilarity in TG-induced $\mathrm{Ca}^{2+}$ entry may be attributable to differences in SOCE channels or their mechanism of activation between glial and neuronal cells. We found that NBQX decreased glial SOCE by $46 \%$, whereas it decreased neuronal SOCE by $73 \%$. This likely reflects the amount and type of AMPARs in both types of cells (Figure 3B; Verkhratsky and Steinhäuser, 2000). Although glial cells possess functional AMPARs (Pizzo et al., 2001; Lalo et al., 2006), the glial population does not contribute significantly to the total amount of AMPARs when analyzed by Western blot and real-time polymerase chain 
reaction (Orlandi et al., 2011). The expression of all four AMPA subunits was detected in rat cortical glia, but the GluA2 subunit was most abundant (Holzwarth et al., 1994). In cortical neurons, GluA1 and GluA2 are the most highly expressed subunits at each stage of development (Orlandi et al., 2011). However, astrocytes have lower expression of $\mathrm{Ca}^{2+}$-permeable AMPARs with Q/R-unedited GluR2 subunits than neurons (Whitney et al., 2008). In cortical astrocytes, AMPARs are stimulated by glutamate and AMPA and can be inhibited by NBQX (Pizzo et al., 2001; Lalo et al., 2011). Glutamate-induced $\mathrm{Ca}^{2+}$ influx in rat cortical astrocytes was also shown to be sensitive to $\mathrm{LaCl}_{3}$, which inhibits SOCE (Pizzo et al., 2001). This work demonstrates that AMPARs appear to be involved in SOCE in neurons, suggesting that the inhibition of these receptors in primary cultures or in the brain would also affect glial SOCE (Figure 3A).

Recently, SOCE in neurons has become the subject of intense research with regard to disturbances in $\mathrm{Ca}^{2+}$ homeostasis that are observed in several neurological disorders, including Alzheimer's disease, Parkinson's disease, Huntington's disease, chronic epilepsy, amyotrophic lateral sclerosis, painful nerve injury and cerebral ischemia (Leissring et al., 2000; BernaErro et al., 2009; Steinbeck et al., 2011; Wu et al., 2011; Czeredys et al., 2013; Kawamata et al., 2014). Because of the high expression of STIM2 in the brain (Berna-Erro et al., 2009; Skibinska-Kijek et al., 2009), lower sensitivity of STIM2 to ER $\mathrm{Ca}^{2+}$ store depletion, and slower oligomerization rate of STIM2 compared with STIM1 (Stathopulos et al., 2009; Hoth and Niemeyer, 2013), STIM2 appears to be the major player in the nervous system. Indeed, disturbances in the pathways that involve STIM2 lead to mushroom spine loss (Sun et al., 2014; Garcia-Alvarez et al., 2015; Popugaeva et al., 2015; Zhang et al., 2015), neuronal injury (Gemes et al., 2011; Rao et al., 2015), and deficits in spatial learning (Berna-Erro et al., 2009). Disturbances in STIM2-associated pathways have also been observed in lymphocytes in familial Alzheimer's disease (Bojarski et al., 2009), brain tissue in ageing mice and humans who suffer from sporadic Alzheimer's disease (Sun et al., 2014;

\section{REFERENCES}

Abdullaev, I. F., Bisaillon, J. M., Potier, M., Gonzalez, J. C., Motiani, R. K., and Trebak, M. (2008). Stim1 and Orail mediate CRAC currents and store-operated calcium entry important for endothelial cell proliferation. Circ. Res. 103, 1289-1299. doi: 10.1161/01.RES.0000338496.95579.56

Akbarian, S., Smith, M. A., and Jones, E. G. (1995). Editing for an AMPA receptor subunit RNA in prefrontal cortex and striatum in Alzheimer's disease, Huntington's disease and schizophrenia. Brain Res. 699, 297-304. doi: 10. 1016/0006-8993(95)00922-d

Arakawa, N., Sakaue, M., Yokoyama, I., Hashimoto, H., Koyama, Y., Baba, A., et al. (2000). KB-R7943 inhibits store-operated $\mathrm{Ca}^{2+}$ entry in cultured neurons and astrocytes. Biochem. Biophys. Res. Commun. 279, 354-357. doi: 10.1006/bbrc. 2000.3968

Baba, A., Yasui, T., Fujisawa, S., Yamada, R. X., Yamada, M. K., Nishiyama, N., et al. (2003). Activity-evoked capacitative $\mathrm{Ca}^{2+}$ entry: implications in synaptic plasticity. J. Neurosci. 23, 7737-7741.

Bain, J., McLauchlan, H., Elliott, M., and Cohen, P. (2003). The specificities of protein kinase inhibitors: an update. Biochem. J. 371, 199-204. doi: 10. 1042/bj20021535
Popugaeva et al., 2015). However, it was recently postulated that synaptopodin regulates activity-dependent $\mathrm{Ca}^{2+}$ signals by recruiting STIM1 and Orail to the postsynaptic density (Korkotian et al., 2014; Segal and Korkotian, 2014) or recruits STIM1 to the postsynaptic density to activate TRPC3 (Hartmann et al., 2014). Moreover, STIM1 inhibits the activity of $\mathrm{Ca}_{V} 1.2$ (Park et al., 2010) and Cav3.1 (Nguyen et al., 2013) VGCCs. Similar to disturbances in SOCE, AMPAR upregulation leads to excessive $\mathrm{Ca}^{2+}$ influx, which may be involved in the neuronal dysfunction that is observed in schizophrenia, Alzheimer's disease, Parkinson's disease, amyotrophic lateral sclerosis, and global ischemia (Akbarian et al., 1995; Pellegrini-Giampietro et al., 1997; O’Neill et al., 2004; Kwak and Kawahara, 2005; Marenco and Weinberger, 2006; Van Den Bosch et al., 2006). Our findings demonstrate that AMPA-mediated $\left[\mathrm{Ca}^{2+}\right]_{i}$ responses in neurons are a part of the SOCE process, suggesting a possible relationship between SOCE, STIM proteins, and AMPARs in these diseases.

In conclusion, the present data demonstrate that SOCE is functional in neurons as an AMPA-dependent $\mathrm{Ca}^{2+}$ signal. Together with the studies by Park et al. (2010) and GarciaAlvarez et al. (2015), our results describe a new role for STIM proteins and SOCE in neuronal signaling by interplaying with the various neuronal $\mathrm{Ca}^{2+}$ channels present in the plasma membrane.

\section{AUTHOR CONTRIBUTIONS}

JG-B conceived, designed and performed experiments, analyzed the data, and wrote the manuscript. MS performed the experiments, analyzed the data, and wrote the manuscript. JK designed the experiments, analyzed the data and wrote the manuscript.

\section{ACKNOWLEDGMENTS}

This study was supported by funds from the National Science Centre (DEC-2011/01/D/NZ3/02051 to JG-B).

Berna-Erro, A., Braun, A., Kraft, R., Kleinschnitz, C., Schuhmann, M. K., Stegner, D., et al. (2009). STIM2 regulates capacitive $\mathrm{Ca}^{2+}$ entry in neurons and plays a key role in hypoxic neuronal cell death. Sci. Signal. 2:ra67. doi: 10. 1126/scisignal.2000522

Berridge, M. J. (1998). Neuronal calcium signaling. Neuron 21, 13-26. doi: 10. 1016/s0896-6273(00)80510-3

Bigge, C. F. (1999). Ionotropic glutamate receptors. Curr. Opin. Chem. Biol. 3, 441-447. doi: 10.1016/S1367-5931(99)80065-9

Bojarski, L., Pomorski, P., Szybinska, A., Drab, M., Skibinska-Kijek, A., Gruszczynska-Biegala, J., et al. (2009). Presenilin-dependent expression of STIM proteins and dysregulation of capacitative $\mathrm{Ca}^{2+}$ entry in familial Alzheimer's disease. Biochim. Biophys. Acta 1793, 1050-1057. doi: 10.1016/j. bbamcr.2008.11.008

Brandman, O., Liou, J., Park, W. S., and Meyer, T. (2007). STIM2 is a feedback regulator that stabilizes basal cytosolic and endoplasmic reticulum $\mathrm{Ca}^{2+}$ levels. Cell 131, 1327-1339. doi: 10.1016/j.cell.2007.11.039

Cahalan, M. D. (2009). STIMulating store-operated $\mathrm{Ca}^{2+}$ entry. Nat. Cell Biol. 11, 669-677. doi: 10.1038/ncb0609-669

Clapham, D. E. (2007). Calcium signaling. Cell 131, 1047-1058. doi: 10.1016/j.cell. 2007.11 .028 
Czeredys, M., Gruszczynska-Biegala, J., Schacht, T., Methner, A., and Kuznicki, J. (2013). Expression of genes encoding the calcium signalosome in cellular and transgenic models of Huntington's disease. Front. Mol. Neurosci. 6:42. doi: 10. 3389/fnmol.2013.00042

Di Buduo, C. A., Moccia, F., Battiston, M., De Marco, L., Mazzucato, M., Moratti, R., et al. (2014). The importance of calcium in the regulation of megakaryocyte function. Haematologica 99, 769-778. doi: 10.3324/haematol. 2013.096859

Emptage, N. J., Reid, C. A., and Fine, A. (2001). Calcium stores in hippocampal synaptic boutons mediate short-term plasticity, store-operated $\mathrm{Ca}^{2+}$ entry and spontaneous transmitter release. Neuron 29, 197-208. doi: 10.1016/s08966273(01)00190-8

Garcia-Alvarez, G., Lu, B., Yap, K. A., Wong, L. C., Thevathasan, J. V., Lim, L., et al. (2015). STIM2 regulates PKA-dependent phosphorylation and trafficking of AMPARs. Mol. Biol. Cell 26, 1141-1159. doi: 10.1091/mbc.e14-07-1222

Gemes, G., Bangaru, M. L., Wu, H.-E., Tang, Q., Weihrauch, D., Koopmeiners, A. S., et al. (2011). Store-operated $\mathrm{Ca}^{2+}$ entry in sensory neurons: functional role and the effect of painful nerve injury. J. Neurosci. 31, 3536-3549. doi: 10. 1523/jneurosci.5053-10.2011

Gruszczynska-Biegala, J., and Kuznicki, J. (2013). Native STIM2 and ORAI1 proteins form a calcium-sensitive and thapsigargin-insensitive complex in cortical neurons. J. Neurochem. 126, 727-738. doi: 10.1111/jnc. 12320

Gruszczynska-Biegala, J., Pomorski, P., Wisniewska, M. B., and Kuznicki, J. (2011). Differential roles for STIM1 and STIM2 in store-operated calcium entry in rat neurons. PLoS One 6:e19285. doi: 10.1371/journal.pone.0019285

Harraz, O. F., and Altier, C. (2014). STIM1-mediated bidirectional regulation of $\mathrm{Ca}^{2+}$ entry through voltage-gated calcium channels (VGCC) and calcium-release activated channels (CRAC). Front. Cell. Neurosci. 8:43. doi: 10. 3389/fncel.2014.00043

Hartmann, J., Karl, R. M., Alexander, R. P., Adelsberger, H., Brill, M. S., Rühlmann, C., et al. (2014). STIM1 controls neuronal $\mathrm{Ca}^{2+}$ signaling, mGluR1-dependent synaptic transmission and cerebellar motor behavior. Neuron 82, 635-644. doi: 10.1016/j.neuron.2014.03.027

Hollmann, M., and Heinemann, S. (1994). Cloned glutamate receptors. Annu. Rev. Neurosci. 17, 31-108. doi: 10.1146/annurev.neuro.17.1.31

Holzwarth, J. A., Gibbons, S. J., Brorson, J. R., Philipson, L. H., and Miller, R. J. (1994). Glutamate receptor agonists stimulate diverse calcium responses in different types of cultured rat cortical glial cells. J. Neurosci. 14, 1879-1891.

Hoth, M., and Niemeyer, B. A. (2013). The neglected CRAC proteins: Orai2, Orai3 and STIM2. Curr. Top. Membr. 71, 237-271. doi: 10.1016/b978-0-12407870-3.00010-x

Jonas, P., Racca, C., Sakmann, B., Seeburg, P. H., and Monyer, H. (1994). Differences in $\mathrm{Ca} 2+$ permeability of AMPA-type glutamate receptor channels in neocortical neurons caused by differential GluR-B subunit expression. Neuron 12, 1281-1289. doi: 10.1016/0896-6273(94)90444-8

Kachoei, B. A., Knox, R. J., Uthuza, D., Levy, S., Kaczmarek, L. K., and Magoski, N. S. (2006). A store-operated $\mathrm{Ca}^{2+}$ influx pathway in the bag cell neurons of Aplysia. J. Neurophysiol. 96, 2688-2698. doi: 10.1152/jn.00118.2006

Kawamata, H., Ng, S. K., Diaz, N., Burstein, S., Morel, L., Osgood, A., et al. (2014). Abnormal intracellular calcium signaling and SNARE-dependent exocytosis contributes to SOD1G93A astrocyte-mediated toxicity in amyotrophic lateral sclerosis. J. Neurosci. 34, 2331-2348. doi: 10.1523/jneurosci.268913.2014

Klejman, M. E., Gruszczynska-Biegala, J., Skibinska-Kijek, A., Wisniewska, M. B., Misztal, K., Blazejczyk, M., et al. (2009). Expression of STIM1 in brain and puncta-like co-localization of STIM1 and ORAI1 upon depletion of $\mathrm{Ca}^{2+}$ store in neurons. Neurochem. Int. 54, 49-55. doi: 10.1016/j.neuint.2008.10.005

Korkotian, E., Frotscher, M., and Segal, M. (2014). Synaptopodin regulates spine plasticity: mediation by calcium stores. J. Neurosci. 34, 11641-11651. doi: 10 . 1523/jneurosci.0381-14.2014

Koss, D. J., Riedel, G., Bence, K., and Platt, B. (2013). Store-operated Ca ${ }^{2+}$ entry in hippocampal neurons: regulation by protein tyrosine phosphatase PTP1B. Cell Calcium 53, 125-138. doi: 10.1016/j.ceca.2012.11.004

Kraft, R. (2015). STIM and ORAI proteins in the nervous system. Channels (Austin) 9, 245-252. doi: 10.1080/19336950.2015.1071747

Krapivinsky, G., Krapivinsky, L., Stotz, S. C., Manasian, Y., and Clapham, D. E. (2011). POST, partner of stromal interaction molecule 1 (STIM1), targets
STIM1 to multiple transporters. Proc. Natl. Acad. Sci. U S A 108, 19234-19239. doi: 10.1073/pnas.1117231108

Kwak, S., and Kawahara, Y. (2005). Deficient RNA editing of GluR2 and neuronal death in amyotropic lateral sclerosis. J. Mol. Med. (Berl) 83, 110-120. doi: 10. 1007/s00109-004-0599-Z

Lalo, U., Pankratov, Y., Kirchhoff, F., North, R. A., and Verkhratsky, A. (2006). NMDA receptors mediate neuron-to-glia signaling in mouse cortical astrocytes. J. Neurosci. 26, 2673-2683. doi: 10.1523/jneurosci.4689-05.2006

Lalo, U., Pankratov, Y., Parpura, V., and Verkhratsky, A. (2011). Ionotropic receptors in neuronal-astroglial signalling: what is the role of "excitable" molecules in non-excitable cells. Biochim. Biophys. Acta 1813, 992-1002. doi: 10.1016/j.bbamcr.2010.09.007

Lei, S., Czerwinska, E., Czerwinski, W., Walsh, M. P., and MacDonald, J. F. (2001). Regulation of NMDA receptor activity by F-actin and myosin light chain kinase. J. Neurosci. 21, 8464-8472.

Leissring, M. A., Akbari, Y., Fanger, C. M., Cahalan, M. D., Mattson, M. P., and LaFerla, F. M. (2000). Capacitative calcium entry deficits and elevated luminal calcium content in mutant presenilin-1 knockin mice. J. Cell Biol. 149, 793-798. doi: $10.1083 /$ jcb.149.4.793

Li, X., Chen, W., Zhang, L., Liu, W. B., and Fei, Z. (2013). Inhibition of store-operated calcium entry attenuates $\mathrm{MPP}^{+}$-induced oxidative stress via preservation of mitochondrial function in PC12 cells: involvement of Homerla. PLoS One 8:e83638. doi: 10.1371/journal.pone.0083638

Lin, A. H., Sun, H., Paudel, O., Lin, M.-J., and Sham, J. S. (2016). Conformation of ryanodine receptor-2 gates store-operated calcium entry in rat pulmonary arterial myocytes. Cardiovasc. Res. 111, 94-104. doi: 10.1093/cvr/cvw067

Majewski, L., and Kuznicki, J. (2015). SOCE in neurons: signaling or just refilling? Biochim. Biophys. Acta 1853, 1940-1952. doi: 10.1016/j.bbamcr.2015.01.019

Marenco, S., and Weinberger, D. R. (2006). Therapeutic potential of positive AMPA receptor modulators in the treatment of neuropsychiatric disorders. CNS Drugs 20, 173-185. doi: 10.2165/00023210-200620030-00001

Markram, H., Toledo-Rodriguez, M., Wang, Y., Gupta, A., Silberberg, G., and Wu, C. (2004). Interneurons of the neocortical inhibitory system. Nat. Rev. Neurosci. 5, 793-807. doi: 10.1038/nrn1519

Martin, L. J., Blackstone, C. D., Levey, A. I., Huganir, R. L., and Price, D. L. (1993). AMPA glutamate receptor subunits are differentially distributed in rat brain. Neuroscience 53, 327-358. doi: 10.1016/0306-4522(93)90199-p

Moccia, F., Zuccolo, E., Soda, T., Tanzi, F., Guerra, G., Mapelli, L., et al. (2015). Stim and Orai proteins in neuronal $\mathrm{Ca}^{2+}$ signaling and excitability. Front. Cell. Neurosci. 9:153. doi: 10.3389/fncel.2015.00153

Nguyen, N., Biet, M., Simard, E., Béliveau, E., Francoeur, N., Guillemette, G., et al. (2013). STIM1 participates in the contractile rhythmicity of HL-1 cells by moderating T-type $\mathrm{Ca}^{2+}$ channel activity. Biochim. Biophys. Acta 1833 , 1294-1303. doi: 10.1016/j.bbamcr.2013.02.027

Nowak, L., Bregestovski, P., Ascher, P., Herbet, A., and Prochiantz, A. (1984). Magnesium gates glutamate-activated channels in mouse central neurones. Nature 307, 462-465. doi: 10.1038/307462a0

O’Neill, M. J., Bleakman, D., Zimmerman, D. M., and Nisenbaum, E. S. (2004). AMPA receptor potentiators for the treatment of CNS disorders. Curr. Drug Targets CNS Neurol. Disord. 3, 181-194. doi: 10.2174/1568007043337508

Orlandi, C., La Via, L., Bonini, D., Mora, C., Russo, I., Barbon, A., et al. (2011). AMPA receptor regulation at the mRNA and protein level in rat primary cortical cultures. PLoS One 6:e25350. doi: 10.1371/journal.pone.0025350

Parekh, A. B., and Putney, J. W. Jr. (2005). Store-operated calcium channels. Physiol. Rev. 85, 757-810. doi: 10.1152/physrev.00057.2003

Park, C. Y., Shcheglovitov, A., and Dolmetsch, R. (2010). The CRAC channel activator STIM1 binds and inhibits L-type voltage-gated calcium channels. Science 330, 101-105. doi: 10.1126/science.1191027

Pellegrini-Giampietro, D. E., Gorter, J. A., Bennett, M. V., and Zukin, R. S. (1997). The GluR2 (GluR-B) hypothesis: $\mathrm{Ca}^{2+}$-permeable AMPA receptors in neurological disorders. Trends Neurosci. 20, 464-470. doi: 10.1016/s01662236(97)01100-4

Pizzo, P., Burgo, A., Pozzan, T., and Fasolato, C. (2001). Role of capacitative calcium entry on glutamate-induced calcium influx in type-I rat cortical astrocytes. J. Neurochem. 79, 98-109. doi: 10.1046/j.1471-4159.2001.00539.x

Popugaeva, E., Pchitskaya, E., Speshilova, A., Alexandrov, S., Zhang, H., Vlasova, O., et al. (2015). STIM2 protects hippocampal mushroom spines from amyloid synaptotoxicity. Mol. Neurodegener. 10:37. doi: 10.1186/s13024-015-0034-7 
Potier, M., Gonzalez, J. C., Motiani, R. K., Abdullaev, I. F., Bisaillon, J. M., Singer, H. A., et al. (2009). Evidence for STIM1- and Orail-dependent storeoperated calcium influx through ICRAC in vascular smooth muscle cells: role in proliferation and migration. FASEB J. 23, 2425-2437. doi: 10.1096/fj.09131128

Potier, M., and Trebak, M. (2008). New developments in the signaling mechanisms of the store-operated calcium entry pathway. Pflugers Arch. 457, 405-415. doi: 10.1007/s00424-008-0533-2

Prakriya, M., and Lewis, R. S. (2015). Store-operated calcium channels. Physiol. Rev. 95, 1383-1436. doi: 10.1152/physrev.00020.2014

Putney, J. W. Jr. (1986). A model for receptor-regulated calcium entry. Cell Calcium 7, 1-12. doi: 10.1016/0143-4160(86)90026-6

Rao, W., Peng, C., Zhang, L., Su, N., Wang, K., Hui, H., et al. (2016). Homerla attenuates glutamate-induced oxidative injury in HT-22 cells through regulation of store-operated calcium entry. Sci. Rep. 6:33975. doi: 10. 1038/srep33975

Rao, W., Zhang, L., Peng, C., Hui, H., Wang, K., Su, N., et al. (2015). Downregulation of STIM2 improves neuronal survival after traumatic brain injury by alleviating calcium overload and mitochondrial dysfunction. Biochim. Biophys. Acta 1852, 2402-2413. doi: 10.1016/j.bbadis.2015. 08.014

Saitoh, M., Ishikawa, T., Matsushima, S., Naka, M., and Hidaka, H. (1987). Selective inhibition of catalytic activity of smooth muscle myosin light chain kinase. J. Biol. Chem. 262, 7796-7801.

Salido, G. M., Jardin, I., and Rosado, J. A. (2011). The TRPC ion channels: association with Orail and STIM1 proteins and participation in capacitative and non-capacitative calcium entry. Adv. Exp. Med. Biol. 704, 413-433. doi: 10. 1007/978-94-007-0265-3_23

Sánchez-Hernández, Y., Laforenza, U., Bonetti, E., Fontana, J., Dragoni, S., Russo, M., et al. (2010). Store-operated $\mathrm{Ca}^{2+}$ entry is expressed in human endothelial progenitor cells. Stem Cells Dev. 19, 1967-1981. doi: 10.1089/scd. 2010.0047

Segal, M., and Korkotian, E. (2014). Endoplasmic reticulum calcium stores in dendritic spines. Front. Neuroanat. 8:64. doi: 10.3389/fnana.2014.00064

Shim, A. H., Tirado-Lee, L., and Prakriya, M. (2015). Structural and functional mechanisms of CRAC channel regulation. J. Mol. Biol. 427, 77-93. doi: 10. 1016/j.jmb.2014.09.021

Shin, D. M., Son, A., Park, S., Kim, M. S., Ahuja, M., and Muallem, S. (2016). The TRPCs, Orais and STIMs in ER/PM junctions. Adv. Exp. Med. Biol. 898, 47-66. doi: 10.1007/978-3-319-26974-0_3

Skibinska-Kijek, A., Wisniewska, M. B., Gruszczynska-Biegala, J., Methner, A., and Kuznicki, J. (2009). Immunolocalization of STIM1 in the mouse brain. Acta Neurobiol. Exp. (Wars) 69, 413-428.

Smyth, J. T., Dehaven, W. I., Bird, G. S., and Putney, J. W. Jr. (2008). Ca ${ }^{2+}$-storedependent and -independent reversal of Stim1 localization and function. J. Cell Sci. 121, 762-772. doi: 10.1242/jcs.023903

Song, I., and Huganir, R. L. (2002). Regulation of AMPA receptors during synaptic plasticity. Trends Neurosci. 25, 578-588. doi: 10.1016/s0166-2236(02) 02270-1

Stathopulos, P. B., Zheng, L., and Ikura, M. (2009). Stromal interaction molecule (STIM) 1 and STIM2 calcium sensing regions exhibit distinct unfolding and oligomerization kinetics. J. Biol. Chem. 284, 728-732. doi: 10.1074/jbc. C800178200

Steinbeck, J. A., Henke, N., Opatz, J., Gruszczynska-Biegala, J., Schneider, L., Theiss, S., et al. (2011). Store-operated calcium entry modulates neuronal network activity in a model of chronic epilepsy. Exp. Neurol. 232, 185-194. doi: 10.1016/j.expneurol.2011.08.022

Sun, S., Zhang, H., Liu, J., Popugaeva, E., Xu, N. J., Feske, S., et al. (2014). Reduced synaptic STIM2 expression and impaired store-operated calcium entry cause destabilization of mature spines in mutant presenilin mice. Neuron 82, 79-93. doi: 10.1016/j.neuron.2014.02.019

Van Den Bosch, L., Van Damme, P., Bogaert, E., and Robberecht, W. (2006). The role of excitotoxicity in the pathogenesis of amyotrophic lateral sclerosis. Biochim. Biophys. Acta 1762, 1068-1082. doi: 10.1016/j.bbadis.2006.05.002

Venkiteswaran, G., and Hasan, G. (2009). Intracellular $\mathrm{Ca}^{2+}$ signaling and store-operated $\mathrm{Ca}^{2+}$ entry are required in Drosophila neurons for flight. Proc. Natl. Acad. Sci. U S A 106, 10326-10331. doi: 10.1073/pnas.0902982106

Verkhratsky, A., and Kettenmann, H. (1996). Calcium signalling in glial cells. Trends Neurosci. 19, 346-352. doi: 10.1016/0166-2236(96)10048-5

Verkhratsky, A., and Steinhäuser, C. (2000). Ion channels in glial cells. Brain Res. Rev. 32, 380-412. doi: 10.1016/s0165-0173(99)00093-4

Wang, Y., Deng, X., Mancarella, S., Hendron, E., Eguchi, S., Soboloff, J., et al. (2010). The calcium store sensor, STIM1, reciprocally controls Orai and Cav 1.2 channels. Science 330, 105-109. doi: 10.1126/science.1191086

Wang, Y. W., Zhang, J. H., Yu, Y., Yu, J., and Huang, L. (2016). Inhibition of store-operated calcium entry protects endothelial progenitor cells from $\mathrm{H}_{2} \mathrm{O}_{2}$-induced apoptosis. Biomol. Ther. (Seoul) 24, 371-379. doi: 10 . 4062/biomolther.2015.130

Watanabe, H., Takahashi, R., Zhang, X. X., Kakizawa, H., Hayashi, H., and Ohno, R. (1996). Inhibition of agonist-induced $\mathrm{Ca}^{2+}$ entry in endothelial cells by myosin light-chain kinase inhibitor. Biochem. Biophys. Res. Commun. 225, 777-784. doi: 10.1006/bbrc.1996.1250

Whitney, N. P., Peng, H., Erdmann, N. B., Tian, C., Monaghan, D. T., and Zheng, J. C. (2008). Calcium-permeable AMPA receptors containing Q/R-unedited GluR2 direct human neural progenitor cell differentiation to neurons. FASEB J. 22, 2888-2900. doi: 10.1096/fj.07-104661

Wu, J., Shih, H. P., Vigont, V., Hrdlicka, L., Diggins, L., Singh, C., et al. (2011). Neuronal store-operated calcium entry pathway as a novel therapeutic target for Huntington's disease treatment. Chem. Biol. 18, 777-793. doi: 10.1016/j. chembiol.2011.04.012

Xia, J., Pan, R., Gao, X., Meucci, O., and Hu, H. (2014). Native store-operated calcium channels are functionally expressed in mouse spinal cord dorsal horn neurons and regulate resting calcium homeostasis. J. Physiol. 592, 3443-3461. doi: 10.1113/jphysiol.2014.275065

Zhang, H., Wu, L., Pchitskaya, E., Zakharova, O., Saito, T., Saido, T., et al. (2015). Neuronal store-operated calcium entry and mushroom spine loss in amyloid precursor protein knock-in mouse model of Alzheimer's disease. J. Neurosci. 35, 13275-13286. doi: 10.1523/JNEUROSCI.1034-15.2015

Conflict of Interest Statement: The authors declare that the research was conducted in the absence of any commercial or financial relationships that could be construed as a potential conflict of interest.

Copyright (c) 2016 Gruszczynska-Biegala, Sladowska and Kuznicki. This is an open-access article distributed under the terms of the Creative Commons Attribution License (CC BY). The use, distribution and reproduction in other forums is permitted, provided the original author(s) or licensor are credited and that the original publication in this journal is cited, in accordance with accepted academic practice. No use, distribution or reproduction is permitted which does not comply with these terms. 